\title{
Sustainable energy transition in Central Asia: status and challenges
}

\author{
Mirjana Radovanović ${ }^{*}$, Sanja Filipović ${ }^{2}$ and Andrea Andrejević Panić ${ }^{3}$
}

\begin{abstract}
Background: The paper aims at gaining insight into the implementation of the process of sustainable energy transition in the countries of Central Asia: Kazakhstan, Kyrgyz Republic, Tajikistan, Turkmenistan, and Uzbekistan. Information and scientific studies on the situation in these countries is scarce. On the other hand, these are resource-rich countries, some are exporters, and all are energy transit countries. The main aim of the paper was realized by applying the energy policies and regulatory framework analysis, defining priorities and monitoring selected indicators prescribed by the International Energy Agency.

Methods: The following methods were used in the quantitative analysis: measurement of data intercorrelation; Pearson test of correlation; principal component analysis (with rotation method: Oblimin with Kaiser normalization); KaiserMeyer-Olkin measure of sampling adequacy, Bartlett's test of sphericity and t-test. The period covered by the quantitative analysis: 1990-2018, provided that the available data for 2019 or 2020 were used in certain cases.

Results: Sustainable energy transition is, at the analysis of policies and data, at a low level. There is no adequate regulatory framework in these countries. The energy transition takes place exclusively within the framework of providing enough energy, without regard to sustainability, while even energy exporting countries are not making efforts to achieve a sustainable energy transition.

Conclusions: There are no indications that the energy transition in the countries of Central Asia will take place according to the standards of the European Union or global bodies. On the other hand, having in mind the natural resources of the mentioned countries and the specific geopolitical position, monitoring the changes is of special importance. The impact of changes on sustainability can be determined mainly ex post.
\end{abstract}

Keywords: Sustainable energy transition, Central Asia, Policy analysis, Data processing, Monitoring optimization

\section{Background}

The transition of the energy sector is one of the priorities of sustainable development. Inadequate exploitation, production and use of energy products cause a significant damage to the environment, and therefore global initiatives have been launched to create and implement multisectoral activities in the field of energy, both on the side of energy production and on the side of consumption.

\footnotetext{
*Correspondence: mirjana.radovanovic@educons.edu.rs

${ }^{1}$ Faculty of Security Studies, Educons University, Vojvode Putnika 87, 21208 Sremska Kamenica, Serbia

Full list of author information is available at the end of the article
}

Most countries have listed sustainable energy transition as a priority in their national strategic documents, along with the adoption of adequate regulations and the definition of financing methods, implementation monitoring and the control of the achieved results.

The European Union is a key stakeholder and leader of sustainable energy transition and introduction of low carbon economy. It has been continuously implementing these activities for decades and aims to be climate-neutral by 2050-an economy with net-zero greenhouse gas emissions by 2050 [1]. Apart from the European Union, other developed countries are in the process of sustainable energy transition. On the other hand, a sustainable original author(s) and the source, provide a link to the Creative Commons licence, and indicate if changes were made. The images or other third party material in this article are included in the article's Creative Commons licence, unless indicated otherwise in a credit line to the material. If material is not included in the article's Creative Commons licence and your intended use is not permitted by statutory regulation or exceeds the permitted use, you will need to obtain permission directly from the copyright holder. To view a copy of this licence, visit http://creativecommons.org/licenses/by/4.0/. The Creative Commons Public Domain Dedication waiver (http://creativeco mmons.org/publicdomain/zero/1.0/) applies to the data made available in this article, unless otherwise stated in a credit line to the data. 
energy transition in developing countries is slow, while many countries have limited data and non-transparent strategic documents.

There is a clear need for a sustainable energy transition in all countries, given the global nature of the sustainable concept and the issue of climate change. When it comes to developing countries, it is necessary to consider the political, technological, social, cultural, historical and many other aspects that may be relevant to the energy transition [2]. Previous studies show that energy transition is slow in these countries, primarily due to the unclear impact of energy transition on the economy and citizens' social position. Therefore, their policy-makers maintain a long-term balance between protectionism on the one hand, and declarative support for energy transition on the other [3], which especially characterizes some hydrocarbon-rich countries, with a historical tradition of centralized management and a significant impact on geopolitical changes [4].

The paper aims at observing the country profile and the status of sustainable energy transition in Central Asian countries (Kazakhstan, Kyrgyz Republic, Tajikistan, Turkmenistan and Uzbekistan), based on the analysis of the available reports and indicators. All these countries went through an economic crisis immediately after gaining independence (1991), followed by a process of stabilization and economic recovery. Since the first goal was economic development, no special attention was paid to energy efficiency and environmental issues, which is characteristic of countries in the early stages of development [5], but such a trend has persisted to this day. Even three decades after the collapse of the USSR, the energy sector in these countries has a centralized administration and control, poor governance effectiveness and efficiency [6] and high corruption [7]. Pollution levels are high due to the old and unmaintained infrastructure (especially in the electrical power sector), and given that all countries were part of the former USSR, the energy sector is highly technically interconnected and enclosed [8]. Energy supply and prices are seen as issues pertaining to social policy and not to energy economics. Governments are slow in their actions regarding the energy transition because they fear destabilization, loss of control and power due to potential socio-economic turbulences [9]. Energy transition is particularly hindered in countries rich in energy resources [10]. Furthermore, there is a high risk of resource curse because of many resource-rich countries and underdeveloped regulatory framework [11].

Countries in the region have significant renewable energy potentials, but they are underutilized due to multiple political, financial, technical and social barriers [12]. The transition to a market economy, which is one of the preconditions for a successful energy transition, is taking place slowly and with varying intensity in the countries of Central Asia. Kazakhstan and Kyrgyzstan have taken a step towards market transition, Tajikistan is following them, while Turkmenistan and Uzbekistan are clearly lagging behind [13].

Sustainable energy transition is a complex undertaking, having its economic, financial, social, environmental, technical, institutional, geopolitical and many other aspects. It requires analysis of the situation, planning, scenario analysis, and the application of adequate methods for monitoring the success of implementation [14]. The main goal of this paper is to analyse the available data, which will provide insight into the current status of sustainable energy transition in Central Asia, highlighting the activities that can mostly contribute to energy transition under given conditions. Finally, the paper provides policy and methodological recommendations.

\section{Methods}

The research sample consists of a total of 5 Central Asian countries: Kazakhstan, Kyrgyzstan, Tajikistan, Turkmenistan and Uzbekistan.

The policy review was conducted by reviewing available official documents and reports. The most comprehensive data were obtained by reviewing Eastern Europe, Caucasus and Central Asia: Energy policies beyond IEA countries, IEA, 2015 [15], and were supplemented by observations from additional scientific literature and reports.

Central Asian countries did not have a developed and harmonized statistical database, so for decades official data were almost inaccessible to the general public or were inconsistent and therefore unreliable. Using the INOGATE programme [16], as one of the oldest projects of the European Commission, the European Union has provided technical assistance to 11 countries (including Central Asian countries) in several areas of energy development, including set-up of energy statistics. The main goal of introducing adequate energy statistics in the mentioned countries is to contribute to adequate planning and monitoring of energy transition, which enabled the conceptualization and implementation of research in this paper.

Measurement of data intercorrelation; Pearson test of correlation; principal component analysis (with rotation method: Oblimin with Kaiser normalization); KaiserMeyer-Olkin measure of sampling adequacy, Bartlett's test of sphericity and t-test were used for data processing. Quantitative analysis includes mostly series for the period 1990-2018, but in some cases the data for 2019 or 2020 are also used. 
Data for a total of 10 indicators were processed, and according to the IEA, the first three are indicators of the success of the energy transition:

1. $\mathrm{CO}_{2}$ emissions per unit of GDP $(\mathrm{kg} \mathrm{CO}$ per 2015 USD);

2. $\mathrm{CO}_{2}$ intensity of power index $(2000=100)$; and

3. Renewable share in final energy consumption (\%).

The remaining 7 indicators are:

1. Energy intensity per unit of GDP MJ/USD (2011 PPP);

2. Carbon intensity of industry energy consumption $\left(\mathrm{gCO}_{2} / \mathrm{MJ}\right)$;

3. Coal final consumption in industry (ktoe);

4. Electricity consumption per capita (MWh/capita);

5. Oil products final consumption-transport (ktoe);

6. Net energy imports (Mtoe); and

7. GDP per capita PPP (current international USD) is here used as an indicator of the degree of socio-economic development of a society, bearing in mind that the countries of Central Asia are developing countries, which certainly affects policy priorities.

The indicator GDP per capita PPP (current international USD) was obtained by inspecting the database of the World Bank [17], while other indicators were obtained by inspecting the database of the International Energy Agency [18].

By applying the selected explorative methods, the historical trend, the correlation of the selected indicators, as well as the assessment of the reliability of the applied methods are determined (with the aim of gaining insight into methodological correctness).

\section{Results}

\section{Energy policy overview}

All Central Asian countries were members of the USSR, and after its disintegration they embarked on the path of independence. During the 1990s, they were hit by crises in all areas, followed by gradual consolidation when each country chose its own path of development. To this end, each country defined certain policies for the energy sector development, which is the subject of this part of the analysis, where 2020 is the last year for which the sources were considered. The main objectives of the policy review are as follows:

1. Determining the (non)existence of national strategic documents covering energy and climate change policy;
2. Defining the situation regarding the liberalization of energy market and energy prices;

3. A brief review of the investment climate; and

4. Reviewing the (non)existence of mutual cooperation between Central Asian countries, as well as cooperation with other countries.

Kazakhstan is a net exporter of energy products, primarily natural gas and coal, with substantial proven reserves. In addition to its abundance of fossil fuels, Kazakhstan has about $20 \%$ of the world's uranium reserves, while its potential for solar energy production is estimated at 3,500,000 TW. The main goals of sustainable energy transition in Kazakhstan relate to the power sector, where electricity generation meets national needs, and they imply improvements to existing thermal power plants that are dominant [19], as well as the transition to clean coal technologies. The creation of a free market and a spot market is underway. Studies show that the implementation of a $100 \%$ renewable power system in Kazakhstan is technically possible and economically viable, but that there are preconditions, above all, in the form of political will and full openness to foreign investors [20, 21].

Unlike Kazakhstan, Kyrgyz Republic has no significant energy reserves, and since the collapse of the USSR has failed to achieve adequate economic progress. Therefore, the poverty rate is still high (22.4\%), making it difficult to prioritize the energy transition [22]. Kyrgyz Republic imports about $90 \%$ of its natural gas and oil [23]. Electricity is mostly generated from hydropower plants, infrastructure is outdated and poorly maintained, with occasional power cuts and outages, without a plan for investments in near future [24]. Sustainable energy transition is seriously jeopardized by the Government's decision (2010) to quadruple coal production, in order to reduce the country's dependency on electricity imports, at the cost of high pollution and maintaining social peace. Nevertheless, the country is trying to move towards a sustainable energy transition. In March 2020, the government approved a Medium-Term Tariff Policy (MTTP) for 2020-2022 to make electricity, heating and hot water tariffs more cost-reflective while providing affordable energy for the most vulnerable customers. Furthermore, the privatization of the coal sector is planned. Gazprom Kyrgyzstan, as part of Gazprom, has defined an investment plan for the natural gas sector by 2030 .

Tajikistan faces major challenges when it comes to energy sector stability, although it has considerable energy reserves. Electricity is mainly generated by the use of hydro-potential. The price of electricity is, for social reasons, below the actual cost (tariff subsidies are among the highest in the world), with supply issues in rural areas 
[25]. Energy infrastructure is outdated, with numerous cases of long-term supply disruptions, especially during winter [26]. Tajikistan has significantly reduced natural gas imports (after the cut of supply from Uzbekistan in 2013), and increased the share of oil supply (about $78 \%$ ). Sector of electricity, oil and gas is state owned. The investment climate, which could attract potential investors to the energy sector, is showing progress, but remains unfavourable. Funding for research and development in energy sector is negligible.

Turkmenistan ranks fourth in the world in terms of offshore and onshore natural gas reserves, after Iran, the Russian Federation and Qatar [27]. Oil and gas exports account for $85 \%$ of total exports, which is why this Central Asian country is most involved in the global energy market. Turkmenistan is connected to the European Union by a gas pipeline system about $4000 \mathrm{~km}$ long (through the Russian Federation and Ukraine) [28]. Electricity is entirely generated from natural gas [29]. Turkmenistan's economy has been completely closed, but there has been noticeable progress in attracting foreign investments. The implementation of the TAPI pipeline project (Turkmenistan, Afghanistan, Pakistan and India, launched in 2015) is one of the rare examples of strategic cooperation of a Central Asian country with its neighbours, which, besides improving security of supply, certainly has a diplomatic dimension [30]. Abundance of fossil fuels slows progress in the field of investment in renewable energy sources, despite their significant potentials [31]. Legislation drafting in the field of energy efficiency and renewable energy is at an early stage (they are low on the list of priorities in the National Strategy on Climate Change adopted in 2012). Gas flaring is one of the biggest environmental issues in Turkmenistan, but official data are not available. Although energy price subsidies have been reduced since 2013, they still burden the introduction of market operations. The investment climate is improving, but is still limited by non-transparent regulations.

Uzbekistan, like all countries in the Caspian region, has significant reserves of oil and natural gas, and therefore it is completely self-sufficient in this regard. However, it faces significant problems when it comes to electricity. Uzbekistan was supplied with electricity through the unique Central Asia Power Grid, until 2009 when it was disconnected from it, leaving severe consequences for the further development of these countries that are still felt today [32]. Since then, Uzbekistan has been importing electricity only from the Kyrgyz Republic (in exchange for water supply), which itself faces problems in supply stability. The entire energy sector is centralized and state owned. Similar to other countries in the region, tariffs are subsidised by the government and are significantly below cost [33]. Foreign investments exist in Uzbekistan, but in the form of joint ventures, and for now there is no data on their profitability. Decree on Measures to Encourage Alternative Sources of Energy was adopted in 2013, but no significant progress has been made [34].

The re-establishment of the Central Asian Power System (financed by the Asian Development Bank with US\$ 35 million) connecting Uzbekistan, Kyrgyzstan, Tajikistan and Kazakhstan stands out as the most significant investment for improving security of supply in this region. This project will connect the electricity-exporting countries of Kyrgyzstan and Tajikistan with Pakistan and Afghanistan, and thus greatly improve the supply of consumers, especially in rural areas, covering large territories, that face electricity shortages, especially in winter. The project is expected to be operational by the end of 2023 [35].

There are no data available on significant investments in renewable energy sources, in improving energy efficiency or climate change mitigation.

In all Central Asian countries, energy is state owned, with only traces of transition towards open market. There are two possible reasons for this: (a) in case of open energy market, there is a possibility of attracting foreign rent seeking companies (politically, socially and economically not acceptable for policy-makers), and (b) liberalization and increase of energy prices for domestic citizens is socially not acceptable for policy-makers and citizens of these countries.

\section{Data processing}

Defining, implementing and controlling the implementation of energy and climate policies (as well as any other) are complex undertakings, where decision-makers should have support in the form of data and the results of their analysis, in order to define development policies and conduct timely monitoring.

The main objectives of data processing are as follows:

1. Defining correlations between selected data; and

2. Defining proposals for improving the monitoring of sustainable energy transition, adapted to the countries of Central Asia.

\section{Correlations between selected indicators}

As the first step in determining the optimal model for estimating the energy transition, the intercorrelation of the selected indicators was checked. As Table 1 indicates, the existence of many correlations between indicators was found, in both directions (positive and negative). It should be noted that model optimization does not attach much significance to the values nor to the logic of their 


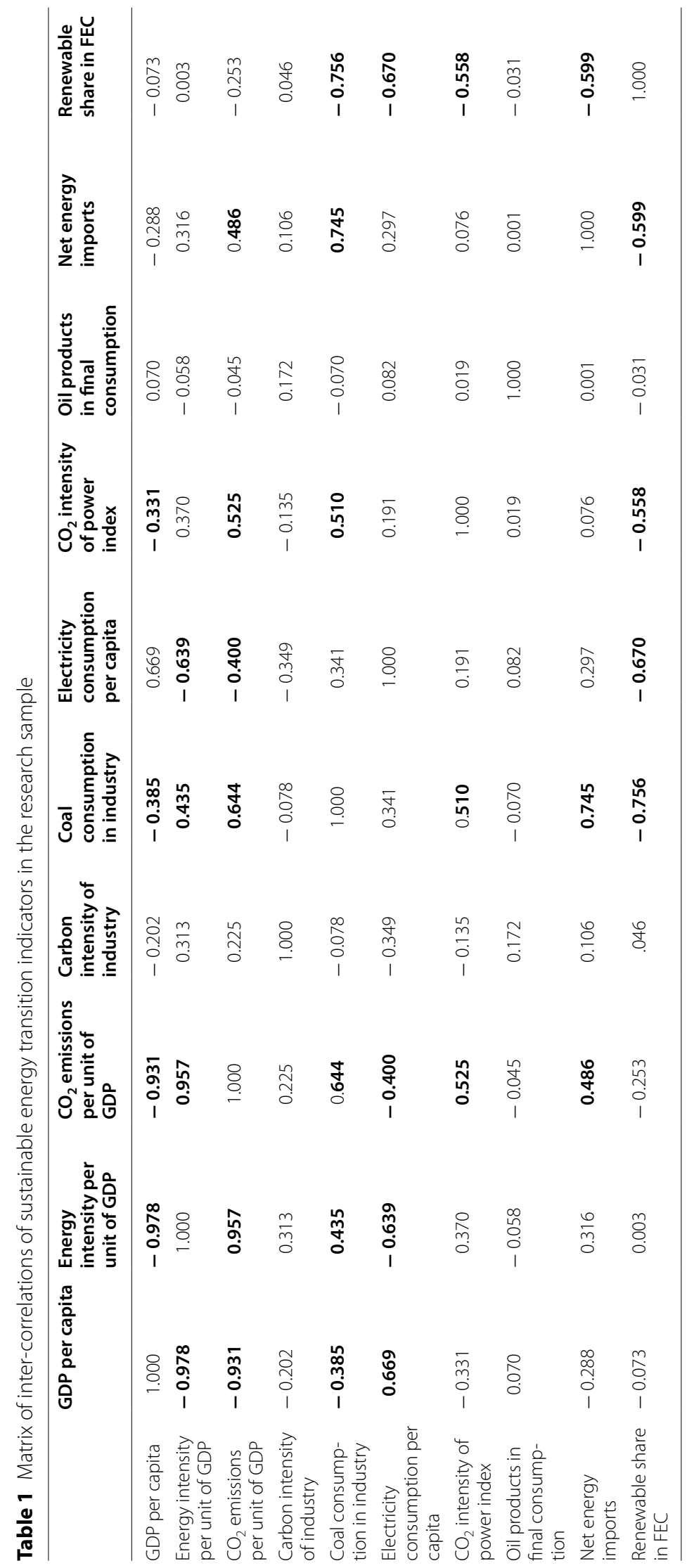


correlations, but to the determination of overlaps from the methodological aspect.

To draw more precise conclusions about statistically significant correlations and overlaps between the indicators, all indicators were subjected to a correlation check using the Pearson correlation coefficient, and the results are shown in Table 2.

Table 2 shows high but negative correlations between GDP per capita and two energy transition indicators: Energy intensity per unit of GDP $(-0.978)$ and $\mathrm{CO}_{2}$ emissions per unit of GDP (-0.933). High correlations between the observed indicators indicate a methodological problem because a high negative correlation means that indicators of equal generality are not used, but total GDP and derived indicators. Furthermore, there is an indicative correlation between GDP per capita and two indicators, which may be of realistic or methodological nature, and which would require further examination, to decide whether certain indicators should be used individually or in a group. In fact, GDP per capita is significantly negatively correlated with coal consumption in industry $(-0.419)$, which means that increased coal consumption leads to a decrease in GDP per capita. Furthermore, GDP per capita is also highly negatively correlated with the $\mathrm{CO}_{2}$ intensity of power index $(-0.420)$, which means that the increased $\mathrm{CO}_{2}$ emissions generated in the process of electricity production and consumption have an impact on GDP per capita reductions. Unexpected and illogical correlations suggest that these indicators should not be used in the group, nor in the eventual formation of an aggregate index.

No significant relationship between coal consumption in industry and carbon intensity of industry (-0.133) is observed. On the other hand, there is a significant positive correlation between coal consumption in industry and $\mathrm{CO}_{2}$ intensity of power index (0.520), which may be due to coal consumption for electricity generation, but not in the case of Turkmenistan and Tajikistan, which receive $95 \%$ of electricity from natural gas, an ecologically very clean energy source.

Net energy imports and renewable share in final energy consumption are highly negatively correlated (-0.599), which is certainly a questionable outcome of the analysis. There is a high negative correlation between renewable share in final energy consumption and electricity consumption per capita $(-0.670)$, which is another indicator that should be kept in mind when optimizing the monitoring model. There is no data on whether the production of electricity from large hydropower plants is considered renewable. Electricity consumption per capita is also highly negatively correlated with the $\mathrm{CO}_{2}$ intensity of power index $(-0.558)$, which means that $\mathrm{CO}_{2}$ emissions decrease, although electricity consumption per capita increases. The input data on renewable share in final energy consumption show that the use of renewable energy sources is at a symbolic level in Kazakhstan, Turkmenistan and Uzbekistan, and therefore high negative correlations are also methodologically questionable and must be borne in mind when optimizing the monitoring model.

\section{Optimization of monitoring models for the degree of sustainable energy transition}

Given the mentioned correlations, several illogicalities are clearly noticeable, too high or too low correlations, some high correlations between indicators that are not logical have been revealed, and consequently there is no clear theoretical framework nor confirmation that these indicators are relevant. Therefore, an exploratory analysis was performed in the next step. The ultimate goal of exploratory factor analysis is the optimization of monitored parameters and models as a whole, by selecting latent factors that can be explained through a small number of specific indicators. Optimization of the monitoring model was performed using factor analysis, for which the principal component analysis method was used. This method is based on the principle of parsimony and looks for potentially simpler and more efficient models.

The basic preconditions for conducting principal component analysis are as follows:

1. All variables used in the model are of interval level of measurements (scale variables, Table 1).

2. The linearity of the parameters used in the analysis was confirmed through Pearson's correlation coefficient of variables (Table 2).

3. Checking the adequacy of the sample based on the Kaiser-Meyer-Olkin test, shows that the minimum value of 0.6 is met (Table 3).

4. Bartlett's test of sphericity confirms that the data in the correlation matrix differ from zero (Table 3).

The results of Kaiser-Meyer-Olkin measure of sampling adequacy (indicating whether the data are generally acceptable for factor analysis), as well as the results of Bartlett's test of sphericity (determining whether there is redundancy between selected indicators) are shown in Table 3.

After the assumptions were confirmed, the data were analysed by using the principal component analysis. Table 4 shows communalities, i.e., how much of variance in each individual parameter can be explained by the selected factors. Having reviewed these values, it is evident that all parameters are well represented in the selected factors and that there is no need to remove any of the selected indicators from the sample. 


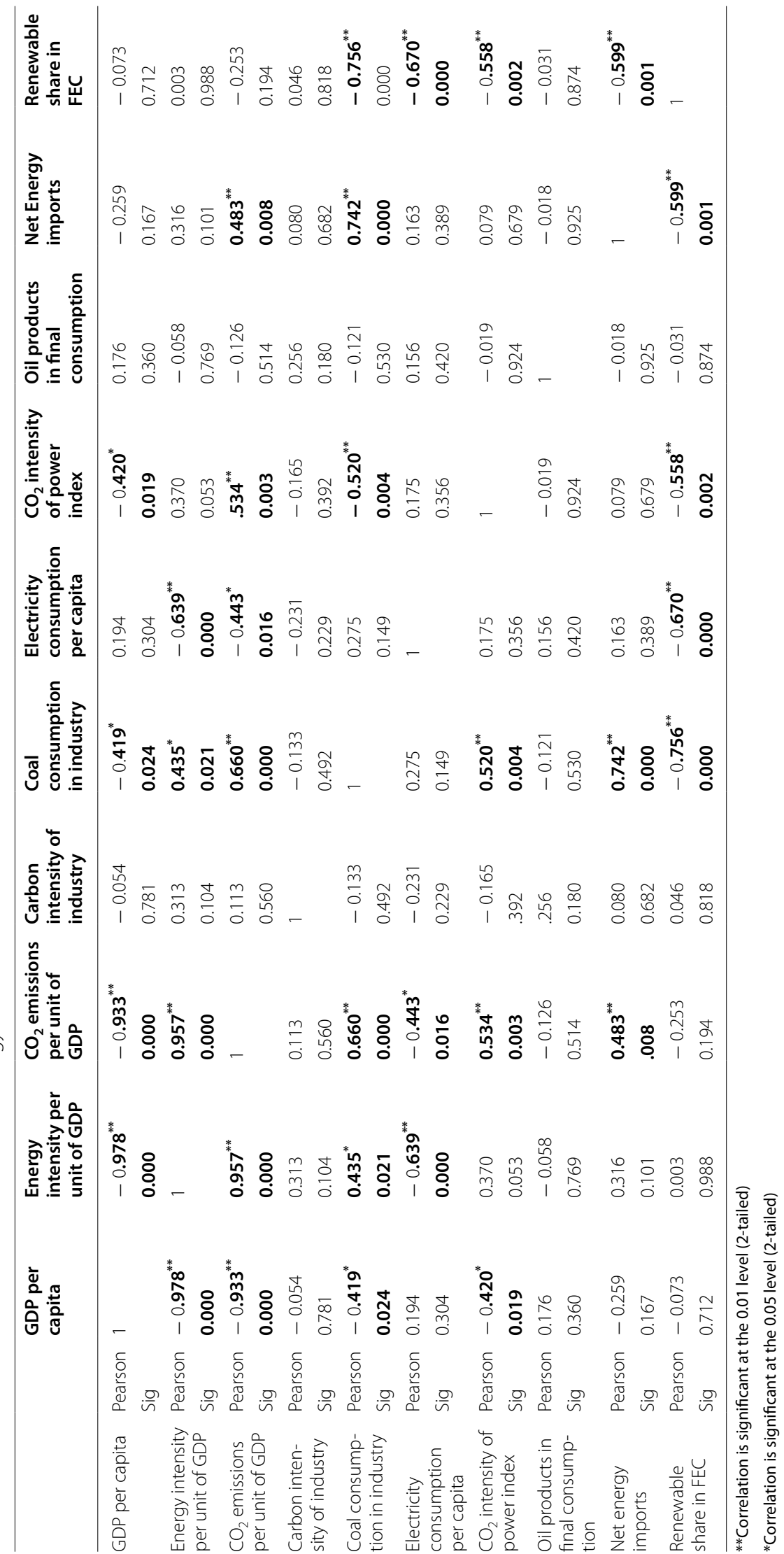


Table 3 Kaiser-Meyer-Olkin measure of sampling adequacy and Bartlett's test of sphericity of sustainable energy transition indicators in the research sample

\begin{tabular}{lll}
\hline Kaiser-Meyer-Olkin measure of sampling adequacy & 0.60 \\
Bartlett's test of & Approx. Chi-square & 385.872 \\
sphericity & df & 45 \\
& Sig & 0.000 \\
\hline
\end{tabular}

Table 4 Communalities of sustainable energy transition indicators in the research sample

\begin{tabular}{lll}
\hline & Initial & Extraction \\
\hline GDP per capita & 1.000 & 0.970 \\
Energy intensity per unit of GDP & 1.000 & 0.993 \\
$\mathrm{CO}_{2}$ emissions per unit of GDP & 1.000 & 0.992 \\
Carbon intensity of industry & 1.000 & 0.676 \\
Coal consumption in industry & 1.000 & 0.901 \\
Electricity consumption per capita & 1.000 & 0.966 \\
$\mathrm{CO}_{2}$ intensity of power index & 1.000 & 0.536 \\
Oil products in final consumption & 1.000 & 0.479 \\
Net energy imports & 1.000 & 0.674 \\
Share of renewable energy in final energy con- & 1.000 & 0.898 \\
sumption & & \\
Extraction method: principal component analysis & & \\
\hline
\end{tabular}

Table 5 shows eigenvalues, i.e., the variances of the selected components. Initially, there are as many components as there are indicators (10 in total), but based on the percentage of explanation of variance, a decision is made on how many should be kept in the final model of estimating the degree of sustainable energy transition in the sampled countries. Based on the rules of roots greater than 1 (Eigenvalues above 1), it is decided that this model can be explained with 3 components, where $81 \%$ of the total variance of all indicators would be covered.

Confirmation of the decision on the three-factor solution can also be seen on the scree plot, where according to the "elbow" rule, the largest drop exists after 3 separated factors (Fig. 1).

Having decided on developing a 3-component model, the factor rotation was selected by using Oblimin rotation, which does not imply orthogonality of the selected factors (since their correlation was determined). Table 6 shows the correlations between components-pattern matrix.

Table 6 shows a significant level of overlap between indicators. Although the simple structure is not completely achieved (parameters present in several components), the obtained solution is quite satisfactory.

\section{Discussion}

The results of the research indicate some specificities of Central Asian countries when it comes to sustainable energy transition, and point to certain conclusions, implications and possible improvements, especially regarding monitoring-which is the central subject of this paper. Furthermore, directly related issues on climate change mitigation, energy poverty and energy market liberalization, which Central Asian countries are to encounter on the path to sustainable energy transition, arise.

The results show that the first component is composed of parameters based on GDP-GDP per capita, Energy intensity per $\mathrm{GDP}$ and $\mathrm{CO}_{2}$ emission per GDP unit. Given the already mentioned issue of the use of several indicators based on GDP, where these are measures of different generalities (as is the case here), it is expected that GDP impact is the first revealed component. However, the biggest issue is electricity consumption per capita which overlaps equally in the first and second components. It is

Table 5 Eigenvalues

\begin{tabular}{|c|c|c|c|c|c|c|}
\hline \multirow[t]{2}{*}{ Component } & \multicolumn{3}{|c|}{ Initial eigenvalues } & \multicolumn{3}{|c|}{ Extraction sums of squared loadings } \\
\hline & Total & $\%$ of variance & Cumulative \% & Total & $\%$ of variance & Cumulative $\%$ \\
\hline 1 & 4.047 & 40.474 & 40.474 & 4.047 & 40.474 & 40.474 \\
\hline 2 & 2.842 & 28.425 & 68.898 & 2.842 & 28.425 & 68.898 \\
\hline 3 & 1.195 & 11.947 & 80.845 & 1.195 & 11.947 & 80.845 \\
\hline 4 & 0.991 & 9.912 & 90.757 & & & \\
\hline 5 & 0.666 & 6.661 & 97.418 & & & \\
\hline 6 & 0.125 & 1.254 & 98.672 & & & \\
\hline 7 & 0.096 & 0.962 & 99.634 & & & \\
\hline 8 & 0.024 & 0.241 & 99.875 & & & \\
\hline 9 & 0.011 & 0.109 & 99.984 & & & \\
\hline 10 & 0.002 & 0.016 & 100.000 & & & \\
\hline
\end{tabular}



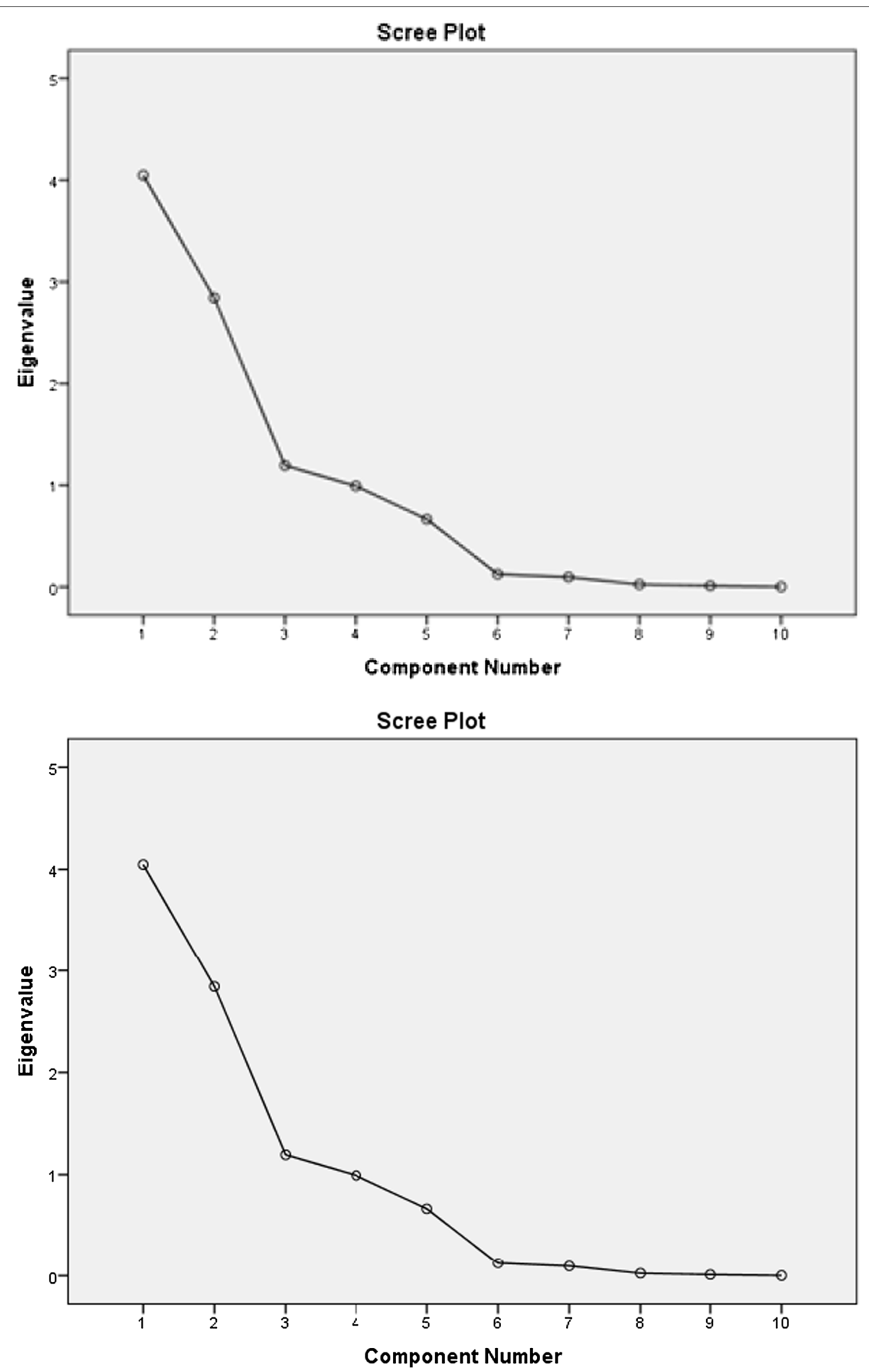

Fig. 1 Scree plot 
Table 6 Matrix of correlations (patterns) between components

\begin{tabular}{llll}
\hline & \multicolumn{3}{l}{ Component } \\
\cline { 2 - 4 } & $\mathbf{1}$ & $\mathbf{2}$ & $\mathbf{3}$ \\
\hline GDP per capita & -0.981 & & \\
Energy intensity per unit of GDP & 0.980 & & \\
$\mathrm{CO}_{2}$ emissions per unit of GDP & 0.886 & & \\
Carbon intensity of industry & -0.782 & 0.681 & \\
Coal consumption in industry & & -0.951 & \\
Electricity consumption per capita & & 0.875 & \\
CO ${ }_{2}$ intensity of power index & & 0.758 & \\
Oil products in final consumption & & 0.537 & \\
Net energy imports & & & 0.749 \\
Share of renewable energy in final & & & 0.681 \\
energy consumption & & & \\
\hline
\end{tabular}

Extraction method: principal component analysis

Rotation method: Oblimin with Kaiser normalization

concluded that this indicator is not well defined (or not well calculated-problems in monitoring), and that on one hand it partly belongs to the components explained by GDP, and on the other hand, to other components that more specifically refer to different energy sources used by sampled countries.

Electricity consumption per capita mostly overlaps with share of renewable energy in final energy consumption, and on the other hand with the following indicators: coal consumption in industry, net energy imports and $\mathrm{CO}_{2}$ intensity of power index. The smallest part of the variance of the model used can be explained through carbon intensity of industry and oil products in final consumption.

Based on the performed exploratory analysis, a proposal was defined for model optimization for monitoring sustainable energy transition in Central Asia, where basic determinants are the following:

- Monitoring GDP per capita for Central Asian countries is preferred, given the fact that these countries are seeking to improve the socio-economic environment, but this indicator can only be used as an auxiliary indicator;

- Indicators based on GDP (carbon intensity and energy intensity) should be monitored, but these two indicators should not be used together, and especially not for creating a possible aggregate index, given a high degree of overlap, which is methodologically incorrect;

- The reasons for the methodological problems observed when using the electricity consumption per capita indicator should be considered. This indicator is important for the energy transition, because it shows most of the overlap with the remaining indi- cators-which makes it methodologically unusable. Given that security of electricity supply activities are a priority in all Central Asian countries, the option is to use this indicator independently, without combining it with others;

- The International Energy Agency does not currently offer the possibility to use two important indicators that would greatly help to describe the status of energy transition in Central Asia: energy poverty, stability of energy infrastructure, power outages and the share of household income allocated for the payment of energy. These are priorities of energy future in Central Asia, and they are not foreseen according to the methodology of the International Energy Agency.

Improving the energy transition monitoring system is certainly necessary, but is also particularly challenging for Central Asian countries. The research used the IEA data, with a clear indication that there are no reliable systems of energy statistics in all of the countries mentioned. The results of this research suggest that the countries of the region should improve their own energy statistics systems (in terms of data collection, quality and transparency), educate and train their own data analysts for data processing, modelling and forecasting, while using modern analytical tools, and involve them in the decision-making process. This is necessary due to a number of challenges that stand in the way of a sustainable energy transition of this region.

First of all, the exploitation of energy resources and energy consumption in Central Asian countries is a particularly challenging issue when it comes to climate change because energy and climate change are closely linked. There are no reliable data on the emission of gases that cause climate change. However, from the data analysed in this paper, it can be concluded that all countries in this region recorded a significant stagnation (even a decline) in economic development until 2000, followed by gradual recovery that is most evident in the case of Kazakhstan, and especially Turkmenistan. Bearing in mind the fact that the Kyrgyz Republic, Uzbekistan and Tajikistan are poor countries with low GDP indicators, it is indirectly concluded that these countries are not and cannot be emitters of gases that cause climate change, as the economy, industry and transport in these countries are at a relatively low level. Carbon-related data used in this paper also support the aforementioned fact. Furthermore, the countries of the region under review use energy generated at hydropower plants, while households in rural areas use natural energy sources. In the case of Kazakhstan and Turkmenistan, natural gas, which is environmentally friendly, is mainly used as an energy source. Kazakhstan also uses nuclear energy, the exploitation 
of which does not contribute to climate change. Coal exploitation is most significant in Kazakhstan, so this country can be considered a country of interest for climate change actions.

Regardless of the specific profile of the countries under review and their vision of energy transition, the main climate change mitigation policies that should be considered in the countries of Central Asia have to be emphasized, and the most important are: changes in energy consumption in households, changes in consumer behaviour, removal of barriers to changes in poor households, removal of economic, institutional and social barriers that slow down the adoption of adequate climate change mitigation policies, as well as the development of the financial support instruments.

Having regard to the available data and the results of the analysis, the issue of energy poverty (as a characteristic of poverty in general) is raised, especially in the Kyrgyz Republic, Uzbekistan and Tajikistan, although certain layer of the population can be considered to be energy poor in Turkmenistan and Kazakhstan, which are energyrich countries. The main problem faced by a certain part of the population in all countries is access to energy. This is due primarily to large expanses and many remote areas, as well as to the interruption of supply from the central power grid that occurred after the collapse of the USSR. In order to solve this problem, significant infrastructure projects are being implemented. The following are recommended as basic measures for energy poverty mitigation in general: control over pricing of energy products, improvement of energy efficiency in households, the use of available renewable sources and increase in household income. On the other hand, the available strategic documents of Central Asian countries show that enabling the supply to consumers in rural areas, stabilizing the network and preventing supply interruptions are at the very top of long-term development priorities, rather than the abovementioned measures.

Decision-makers in Central Asian countries already control the issue of energy poverty, primarily through a complete control over the domestic market. Liberalization of the energy market is defined in the regulatory framework, but it has not been implemented in practice. The energy market is monopolistic, energy prices are highly subsidized by the state, and any announcement of an increase in energy prices for domestic consumers is met with resistance and deterrence by decision-makers. Policy-makers in Central Asian countries implement energy policy taking into account the historical heritage, social policy, and above all the probable negative effects of energy market liberalization: the expected significant increase in energy poverty (which brings on a number of economic and social negative consequences), non-competitiveness of the economy, as well as the danger that may lurk in foreign rent seeking companies, which weak institutions in some countries of this region will probably not be able to control. The traditionally closed nature of Central Asian countries, state policy and low level of readiness for foreign investments are particular issues in this region. There are indications of opening, but foreign capital investments in energy-related projects are relatively small (especially when potentials are taken into account). Due to all the aforementioned issues, the current state of the centralized energy market can be considered an adequate framework for sustainable energy transition in Central Asian countries.

\section{Conclusions}

The performed quantitative analysis reveals that the success of sustainable energy transition, according to the methodology of the International Energy Agency, can be most effectively measured by GDP-based indicators, although there is certainly a large overlap between them, and as such should not be used together. The second separate group of components consists of indicators that describe the type and method of energy use in the economy. However, the research results indicate the problem of applying the electricity consumption per capita indicator due to the high level of overlap in the first two components. The reason may lie in this indicator not being well enough defined (or not well calculated-problems in monitoring), and partly belonging to the components explained by GDP, and on the other hand partly to another component that more specifically refers to different energy sources used by the sampled countries. This is largely in favour of the state policy of Central Asian countries, which regard the issue of electricity supply as a matter of social policy and the fight against energy poverty, rather than a matter of energy transition.

At the beginning of the research period (1990), all Central Asian countries recorded unfavourable values of all indicators. Uzbekistan has the lowest value of GDP per capita (2493.49 USD per capita), while Tajikistan has the lowest growth during the entire period (2641.59 USD per capita in 1990, compared to 3858.42 USD per capita in 2020). Energy intensity per unit of GDP in 1990 was the highest in Uzbekistan (30.6 MJ/USD), the lowest in Turkey (3.5 MJ/USD), while at the end (2017) the values in all Central Asian countries fell (Uzbekistan recorded 7.2 MJ/ USD). $\mathrm{CO}_{2}$ emissions per unit of GDP show consistently low values throughout the period in Turkey and Germany (values below 0), while the decline was recorded by Central Asian countries, where the Kyrgyz Republic recorded the largest decline $\left(4.3 \mathrm{~kg} \mathrm{CO}_{2}\right.$ per USD in 1990, i.e., $1.4 \mathrm{~kg} \mathrm{CO}_{2}$ per USD in 2018). 
The analysis showed high correlations between a large number of indicators (energy intensity per unit of GDP and $\mathrm{CO}_{2}$ emissions per unit of GDP, as well as between coal consumption in industry and $\mathrm{CO}_{2}$ emissions per unit of $G D P$ ), with some being illogical and therefore methodologically questionable.

\section{Acknowledgements}

This paper has been translated by a professional translator Tanja Paunović, Republic of Serbia.

\section{Authors' contributions}

MR prepared concept of the study, participated in data collection, analysis and interpretation of the results. SF was major contributor in literature review, data interpretation and major contributor to policy recommendation. AAP was major contributor in data collection. All authors participated in manuscript editing and approved the final manuscript.

\section{Funding}

First author of this research paper has been supported by Jean Monnet Projects Erasmus + "The circular economy: "the number one priority" for the European Green Deal", Reference Number: 619927-EPP-1-2020-1-BG-EPPJMO-PROJECT.

\section{Availability of data and materials}

The datasets used and/or analysed during the current study are available from the corresponding author on reasonable request.

\section{Declarations}

\section{Ethics approval and consent to participate}

Not applicable.

\section{Consent for publication}

Not applicable.

\section{Competing interests}

The authors declare that they have no competing interests.

\section{Author details}

${ }^{1}$ Faculty of Security Studies, Educons University, Vojvode Putnika 87, 21208 Sremska Kamenica, Serbia. ${ }^{2}$ Institute of Social Sciences, Singidunum University, Danijelova 32, 11000 Belgrade, Serbia. ${ }^{3}$ Faculty of Business Economics, Educons University, Vojvode Putnika 87, 21208 Sremska Kamenica, Serbia.

Received: 6 October 2021 Accepted: 25 November 2021

Published online: 07 December 2021

\section{References}

1. Net zero by 2020: A roadmap for the global energy sector, International Energy Agency, France, https://iea.blob.core.windows.net/assets/4719e 321-6d3d-41a2-bd6b-461ad2f850a8/NetZeroby2050-ARoadmapfortheG lobalEnergySector.pdf. Accessed 14 July 2021

2. Vanegas Cantarero MM (2020) Of renewable energy, energy democracy, and sustainable development: a roadmap to accelerate the energy transition in developing countries. Energy Res Soc Sci 70:101716. https://doi. org/10.1016/j.erss.2020.101716

3. Svobodova K, Owen JR, Harris J, Worden S (2020) Complexities and contradictions in the global energy transition: a re-evaluation of countrylevel factors and dependencies. Appl Energy 265:114778. https://doi.org/ 10.1016/j.apenergy.2020.114778

4. Koch N, Tynkkynen V (2019) The geopolitics of renewables in Kazakhstan and Russia. Geopolitics 26:521-541. https://doi.org/10.1080/14650045. 2019.1583214

5. Joshi P, Beck K (2018) Democracy and carbon dioxide emissions: assessing the interactions of political and economic freedom and the environmental Kuznets curve. Energy Res Soc Sci 39:46-54. https://doi. org/10.1016/j.erss.2017.10.020

6. Stupak I, Mansoor M, Smith CT (2021) Conceptual framework for increasing legitimacy and trust of sustainability governance. Energy, Sustain Soc 11:5. https://doi.org/10.1186/s13705-021-00280-x

7. Junxia $L$ (2019) Investments in the energy sector of Central Asia: corruption risk and policy implications. Energy Policy 133:110912. https:// doi.org/10.1016/j.enpol.2019.110912

8. Ardelean M, Minnebo P, Gerbelova H (2020) Optimal paths for electricity interconnections between Central Asia and Europe. JRC for policy report, European Commission, Luxembourg: Publications Office of the European Union. file:///C:/Users/User/Downloads/centralasia-toeurope_final.pdf

9. Shadrina E (2020) Non-hydropower renewable energy in central Asia: assessment of deployment status and analysis of underlying factors. Energies 13:2963. https://doi.org/10.3390/en13112963

10. Shadrina E (2019) A double paradox of plenty: renewable energy deployment in Central Asia. Eurasian Geogr Econ. https://doi.org/10. 1080/15387216.2020.1823868

11. Biresselioglu ME, Demir MH, Gonca A, Kolcu O, Yeti A (2019) How vulnerable are countries to resource curse? A multidimensional assessment. Energy Res Soc Sci 47:93-101. https://doi.org/10.1016/j.erss. 2018.08.015

12. Nabiyeva K (2020) Fostering the energy transition: prospects for renewable energy and energy efficiency in Sout East and Eastern Europe, South Caucasus and Central Asia, Friedrich Ebert Stiftung, Germany, http://libra ry.fes.de/pdf-files/id-moe/16818.pdf

13. Batsaikhan U, Dabrowski M (2017) Central Asia-twenty-five years after the breakup of the USSR. Russian J Econ 3:296-320. https://doi.org/10. 1016/j.ruje.2017.09.005

14. Podbregar I, Šimić G, Radovanović M, Filipović S, Maletič D, Šprajc P (2020) The international energy security risk index in sustainable energy and economy transition decision making - a reliability analysis. Energies 13:3691. https://doi.org/10.3390/en13143691

15. Eastern Europe, Caucasus and Central Asia: Energy policies beyond IEA countries, IEA, 2015. https://iea.blob.core.windows.net/assets/63aaa8a4d16d-4ff4-84a8-387f440304be/IDR_EasternEuropeCaucasus_2015.pdf

16. INOGATE program, European Commission, 1996, http://www.inogate.org/ pages/1?lang=en

17. International Energy Agency; data base (https://www.iea.org/countries). Accessed 14 July 2021

18. World Bank; data base (https://data.worldbank.org/indicator/NY.GDP PCAP.PP.CD?view=chart). Accessed 22 July 2021

19. Collins N, Bekenova K (2017) Fuelling the New Great Game: Kazakhstan, energy policy and the EU. Asia Europe Journal 15:1-20. https://doi.org/ 10.1007/s10308-016-0451-4

20. Bogdanov D, Toktarova A, Breyer C (2019) Transition towards 100\% renewable power and heat supply for energy intensive economies and severe continental climate conditions: case for Kazakhstan. Appl Energy 253:113606. https://doi.org/10.1016/j.apenergy.2019.113606

21. MacGregor J (2017) Determining an optimal strategy for energy investment in Kazakhstan. Energy Policy 107:210-114. https://doi.org/10.1016/j. enpol.2017.04.039

22. Sabyrbekov R, Ukueva N (2019) Transitions from dirty to clean energy in low-income countries: insights from Kyrgyzstan. Central Asian Survey 38:255-274. https://doi.org/10.1080/02634937.2019.1605976

23. Lee $\mathrm{E}$, Mah JS (2017) (Dekker HAL. Property regimes in transition: land reform, food security and economic development: a case study in the Kyrgyz Republic, Routledge

24. Komendantova N et al (2018) Industrial Development of Kyrgyzstan: Required Infrastructure and Priority Industrial Sectors. International institute for applied system analysis, Austria. http://pure.iiasa.ac.at/id/eprint/ 15500/1/WP-18-014.pdf

25. World Bank (2014) Assessment of Household Energy Deprivation in Tajikistan: Policy Options for Socially Responsible Reform in the Energy Sector. Washington, DC. @ World Bank

26. Laldjebaev M et al (2018) Rethinking energy security and services in practice: national vulnerability and three energy pathways in Tajikistan. Energy Policy 114:39-50. https://doi.org/10.1016/j.enpol.2017.11.058 
27. Esen V, Oral B (2016) Natural gas reserve/production ratio in Russia, Iran, Qatar and Turkmenistan: a political and economic perspective. Energy Policy 93:101-109. https://doi.org/10.1016/j.enpol.2016.02.037

28. Overland I (2016) Energy: the missing link in globalization. Energy Res Soc Sci 14:122-130. https://doi.org/10.1016/j.erss.2016.01.009

29. Turkmenistan. In: The Statesman's Yearbook 2020. The Statesman's Yearbook. Palgrave Macmillan, London. https://doi.org/10.1057/978-1-34995940-2_194

30. Huda MS, Ali SH (2017) Energy diplomacy in South Asia: beyond the security paradigm in accessing the TAPI pipeline project. Energy Res Soc Sci 34:202-213. https://doi.org/10.1016/j.erss.2017.07.013

31. Bahrami A, Teimourian A, Okoye CO, Khosravi N (2019) Assessing the feasibility of wind energy as a power source in Turkmenistan; a major opportunity for Central Asia's energy market. Energy 183:415-427. https://doi.org/10.1016/j.energy.2019.06.108

32. Toralieva G (2009) Destruction of Central Asian Electricity Grid: Causes and Implications. EUCAM Commentary No. 8, 18 December 2009, http:// aei.pitt.edu/13419/1/EUCAM_commentary8_Toralieva.pdf

33. Djalilova N (2021) Sustainable energy in central Asia: transition towards renewable energy sources in Uzbekistan. Routledge. https://doi.org/10. 4324/9781003110071

34. Gomez A, Dopazo C, Fueyo N (2015) The future of energy in Uzbekistan. Energy 85:329-338. https://doi.org/10.1016/j.energy.2015.03.073

35. Mehta K, Ehrenwirth M, TrinkI C, Zörner W, Greenough R (2021) The energy situation in central Asia: a comprehensive energy review focusing on rural areas. Energies 14:2805. https://doi.org/10.3390/en14102805

36. In-Depth Review of the Energy Efficiency Policy of the Kyrgyz Republic, Energy Charter Secretariat, Brussels, Belgium, 2018. https://www.energ ycharter.org/fileadmin/DocumentsMedia/IDEER/IDEER-Kyrgyzstan EN2018.pdf

37. Sustainable Infrastructure Development for a Low-Carbon Transition in Central Asia and the Caucasus: Mapping of Potentially High-impact Infrastructure Projects and Needs Assessment-Strategic Infrastructure Planning for Sustainable Development in Turkmenistan. OECD, 2019

\section{Publisher's Note}

Springer Nature remains neutral with regard to jurisdictional claims in published maps and institutional affiliations.

Ready to submit your research? Choose BMC and benefit from:

- fast, convenient online submission

- thorough peer review by experienced researchers in your field

- rapid publication on acceptance

- support for research data, including large and complex data types

- gold Open Access which fosters wider collaboration and increased citations

- maximum visibility for your research: over $100 \mathrm{M}$ website views per year

At BMC, research is always in progress.

Learn more biomedcentral.com/submissions 